\title{
Therapeutic Dilemmas in Young Patients with Early Stage Endometrial Cancer
}

\author{
Georgios Androutsopoulos*1, Ioannis C Kotsopoulos ${ }^{2}$, Porfyrios Korompelis ${ }^{2}$ and Georgios Decavalas ${ }^{1}$ \\ ${ }^{1}$ Department of Obstetrics and Gynecology, University of Patras, Greece \\ ${ }^{2}$ Northern Gynaecological Oncology Centre, Queen Elizabeth Hospital, UK
}

Submission: May 08, 2017; Published: May 22, 2017

"Correspondence Address: Georgios Androutsopoulos, Assistant Professor, Department of Obstetrics and Gynecology, University of Patras, Medical School, Rion 26504, Greece, Tel: +306974088092; Email: androutsopoulos@upatras.gr

\section{Editorial}

Nowadays, endometrial cancer (EC) is the $2^{\text {nd }}$ most common tumor of the female reproductive system and the $5^{\text {th }}$ most common cancer among female patients [1,2]. It is more frequent in wealthy and more developed countries (Northern and Western Europe, Northern America), while the mortality rate is considerably greater in less developed ones (Northern Africa, Melanesia)[1,2]. Despite the fact that the vast majority of EC patients are postmenopausal, approximately $14 \%$ of them are premenopausal and almost $4 \%$ are below 40 years of age [319]. It is widely believed that conservative management of those young patients with EC, represents a great challenge [3-19].

According to the most recent guidelines, systematic surgical staging plays a fundamental role in EC treatment [3-5,9-15,18,2025]. This is mainly based on the fact that systematic surgical staging provides many advantages in diagnosis, treatment and prognosis for both types of EC [type I (endometrioid) or type II (serous, clear cell, undifferentiated)] [3-5,9-15,18,20-25]. Moreover, postoperative adjuvant treatment (radiotherapy, chemotherapy or a combination of both) plays a crucial role in EC patients with increased risk of recurrence or at advanced disease stage [3-5,9-15,26]. However, the extent of surgical staging and the type of postoperative adjuvant treatment should be thoroughly individualized based on disease stage, type of EC, fertility issues and patient's general performance status [3-5,916,18-15].

Based on the abovementioned, only young patients with FIGO stage IA, grade 1 and type I EC (endometrioid), are suitable for conservative therapeutic approach [3-5,7,16,27-30]. These patients should have intense desire for fertility preservation, informed consent and no contraindications for treatment with progestins $[3,4,7,16,19]$. Moreover, all of them should be referred to oncologic centres specialised in fertility sparing management $[3,4,7,16,19]$.
It is worth noting, that patients should be informed that conservative approach does not represent the standard of care in EC treatment and the available data is very limited [3-5,7,16,19,27-30]. Furthermore, all patients should be thoroughly counselled about disease recurrence, future fertility and childbearing [3-5,7,16,19,27-30]. At the same time, a very close follow-up protocol should be accepted, for an extended time period [3-5,7,16,19,27-30]. In addition, they should be aware of the future need of systematic surgical staging in case of treatment failure or after childbearing [3-5,7,16,19,27-30].

At the beginning of the fertility sparing approach, an appropriate endometrial sample should be obtained from each patient, either with office endometrial biopsy, hysteroscopy or dilatation and curettage $[3,4,7,16,19,31-36]$. The main advantage of dilatation and curettage when compared with other methods, is the provision of a better quality specimen and this is the reason why it is more preferable $[3,4,7,16,19,31-36]$. Subsequently, the provided endometrial sample should be assessed by an expert pathologist, in order to make a precise diagnosis regarding grade and type of EC $[3,4,7,16,19,34]$. A thorough assessment of the entire specimen for hormone receptors (estrogen, progesterone) as well as for molecular prognostic markers (p53, Ki-67, HE-4), may provide additional data about nature and clinical behavior of the specific cancer $[3,4,6,7,16,19,37]$. The role of pathologist is of great importance when considering fertility sparing approach in EC, because based on their findings patients with aggressive types of EC should be excluded from any type of conservative management $[3-5,7,16,19]$.

Apart from that, a detailed visualization of the entire abdomen should be obtained either with ultrasound, computerized tomography (CT) or magnetic resonance imaging (MRI), in order to evaluate the depth of myometrial invasion and identify any disease beyond uterus (ovaries, pelvic and paraaortic lymph nodes and omentum) $[3,4,7,16,19,34,38-40]$. The 
main advantage of MRI when compared with other methods, is the better visualization of these anatomical structures and that is why it is more preferable $[3,4,7,16,19,34,38-42]$. The role of radiologist is really essential when considering fertility preservation in EC, because based on their findings patients with advanced stage disease should be excluded from any conservative approach $[3,4,7,16,19,34,38-40]$.

Moreover, useful information regarding disease stage could be obtained with laparoscopy $[3,7,16,19]$. However, when considering fertility sparing management in patients with EC, the utilization of laparoscopy as an evaluation method still remains optional $[3,7,16,19]$. After completion of pre-treatment evaluation, the eligible patients [FIGO stage IA, grade 1 and type I EC (endometrioid)] could initiate the fertility sparing approach, which is mainly based on the use of oral progestin regimens [3-5,7,16,19,26,43,44]. The most commonly used progestins in daily practise, are medroxyprogesterone acetate (MPA) and megestrol acetate (MA) [3-5,7,14,19,26,34,43,44]. The recommended daily dosage of MPA is 400-600 mg, while that of MA is $160-320 \mathrm{mg}[3-5,7,16,19,34,45]$. The oral progestin regimens should be administered for a period of 6 months, as there are no evidence supporting prolonged treatment in order to achieve a late response [3-5,7,16,19,34,45-47]. However in the past, a lot of patients treated with oral progestins for extended time periods [3-5,7,16,19,34,45-47]. Apart from oral progestins, the administration of intrauterine devices releasing levonorgestrel with or without gonadotropin releasing hormone analogues ( $\mathrm{GnRH}$ analogues) have shown promising results and could be considered as an alternative treatment option $[4,5,16,19,34,43,48]$.

During fertility sparing approach with oral progestins, all patients should be routinely reassessed every 3 months with endometrial sampling, in order to evaluate the response to treatment $[3,4,7,16,19,34,43,49]$. The endometrial sample could be obtained either with hysteroscopy or dilatation and curettage $[3,4,7,16,19,34,43,49]$. After completion of the 6 month therapy with oral progestin regimens, all patients should be further assessed with MRI, in order to evaluate the overall response to treatment $[3,4,7,16,19,34,39,49]$.

If the post-treatment assessment reveals no response to the fertility sparing approach, then systematic surgical staging should be performed in all patients according to the most recent guidelines for EC [3-5,7,9-16,18-21,24,25,34,46,47]. In this case, treatment with oral progestins should not be prolonged in order to achieve a late response, as there are no evidence to support that $[3-5,7,16,19,34,45-47]$. In contrast, if there is a complete response to the fertility sparing management, then patients should be further referred to a fertility centre in order to start an assisted conception protocol [3-5,7,16,19,50-53]. If they do not desire pregnancy at this time, then therapy with oral progestins should be continued and patients should be reassessed every 6 months $[3,4,7,16,19,34,43,50]$.
Based on recently published data, the overall response rate in EC patients treated with oral progestin regimens is quite encouraging reaching almost $75 \%[3,4,7,16,19,29,34,50,54]$. Moreover, there is evidence that pregnancy decreases the risk of EC recurrence $[3,4,7,16,19,43,50]$. After childbearing, systematic surgical staging should be performed in all these patients, because there is significant risk for disease recurrence and the overall recurrence rate is approximately $30-40 \%$ $[3,4,7,16,19,34,50,54]$.

In conclusion, only young patients with FIGO stage IA, grade 1 and type I EC (endometrioid), are suitable for conservative therapeutic approach with oral progestin regimens $[3-5,7,16,19,27-30,55]$. All patients should be extensively counselled regarding disease recurrence, future fertility and childbearing and be aware of the future need of systematic surgical staging in case of treatment failure or after childbearing $[3-5,7,16,19,27-30]$.

\section{Reference}

1. GLOBOCAN (2012) Estimated cancer incidence, mortality and prevalence worldwide in 2012. WHO, Geneva, Switzerland, Europe.

2. Ferlay J, Soerjomataram I, Dikshit R, Eser S, Mathers C, et al. (2015) Cancer incidence and mortality worldwide: sources, methods and major patterns in GLOBOCAN 2012. Int J Cancer 136(5): E359-E386.

3. ACOG (2015) Endometrial cancer. ACOG practice bulletin, Obstet Gynecol 125(4): 1006-1026.

4. Colombo N, Creutzberg C, Amant F, Bosse T, Gonzalez-Martin A, et al. (2016) ESMO-ESGO-ESTRO Consensus Conference on Endometrial Cancer: diagnosis, treatment and follow-up. Ann Oncol 27(1):16-41.

5. Sundar S, Balega J, Crosbie E, Drake A, Edmondson R, et al. (2017) BGCS uterine cancer guidelines: Recommendations for practice. Eur ] Obstet Gynecol Reprod Biol 213: 71-97.

6. Duska L, Garrett A, Rueda B, Haas J, Chang Y, et al. (2001) Endometrial cancer in women 40 years old or younger. Gynecol Oncol 83(2): 388393.

7. Erkanli S, Ayhan A (2010) Fertility-sparing therapy in young women with endometrial cancer: 2010 update. Int J Gynecol Cancer 20(7): 1170-1187.

8. Gitsch G, Hanzal E, Jensen D, Hacker NF (1995) Endometrial cancer in premenopausal women 45 years and younger. Obstet Gynecol 85(4): 504-508.

9. Androutsopoulos G (2012) Current treatment options in patients with endometrial cancer. J Community Med Health Educ 2(12): e113.

10. Androutsopoulos G, Decavalas G (2013) Management of endometrial cancer. Int J Translation Community Dis 1(1): 1-3.

11. Androutsopoulos G, Decavalas G (2014) Endometrial cancer: current treatment strategies. World J Oncol Res 1(1):1-4.

12. Androutsopoulos G, Michail G, Adonakis G, Decavalas G (2015) Current treatment approach of endometrial cancer. Int J Clin Ther Diagn S1(3): 8-11.

13. Androutsopoulos G, Adonakis G, Decavalas G (2015) Present and future in endometrial cancer treatment. Obstet Gynecol Int J 2(2): 00031.

14. Androutsopoulos G, Michail G, Decavalas G (2016) New insights in endometrial cancer treatment. Clinics in Oncology, Endometrial Cancer 1: 1040. 


\section{Cancer Therapy \& Oncology International Journal}

15. Androutsopoulos G, Decavalas G (2016) Standard and novel therapies in endometrial cancer. J Gynecol Women's Health 1(3): 555564.

16. Androutsopoulos G, Kotsopoulos I, Decavalas G (2016) Fertility preservation in young patients with endometrial cancer. World J Oncol Res 3(1): 36-39.

17. Koufopoulos N, Carrer D, Koureas N, Sofopoulos M, Paraoulakis I, et al. (2013) Pathological data on 19 cases of endometrioid carcinoma of the endometrium in women of reproductive age. Int J Gynecol Cancer 23(8): 322

18. Androutsopoulos G, Kotsopoulos I, Korompelis P, Michail G, Adonakis G, et al. (2017) Systematic lymphadenectomy or sentinel lymph node dissection in endometrial cancer: a clinical dilemma. Hel J Obst Gynecol 16(1): 14-19.

19. Androutsopoulos G, Kotsopoulos I, Adonakis G, Decavalas G (2017) Conservative management of young patients with early stage endometrial cancer. J Gynecol Women's Health 2(3): 555586.

20. Burke W, Orr J, Leitao M, Salom E, Gehrig P, et al. (2014) Endometrial cancer: a review and current management strategies: part I. Gynecol Oncol 134(2): 385-392.

21. Pecorelli S (2009) Revised FIGO staging for carcinoma of the vulva, cervix, and endometrium. Int J Gynaecol Obstet 105(2):103-104.

22. Bokhman J (1983) Two pathogenetic types of endometrial carcinoma. Gynecol Oncol 15(1):10-17.

23. Doll A, Abal M, Rigau M, Monge M, Gonzalez M, et al. (2008) Novel molecular profiles of endometrial cancer-new light through old windows. J Steroid Biochem Mol Biol 108(3-5): 221-229.

24. Androutsopoulos G, Kotsopoulos I, Decavalas G (2016) The role of lymphadenectomy in patients with endometrial cancer. J Gynecol Women's Health 1(5): 555573.

25. Androutsopoulos G, Kotsopoulos I, Decavalas G (2016) Sentinel lymph node mapping and dissection in patients with endometrial cancer Trends Gynecol Oncol 1(3): e103.

26. Burke W, Orr J, Leitao M, Salom E, Gehrig P, et al. (2014) Endometrial cancer: a review and current management strategies: part II. Gyneco Oncol 134(2): 393-402.

27. Feichtinger M, Rodriguez Wallberg KA (2016) Fertility preservation in women with cervical, endometrial or ovarian cancers. Gynecol Oncol Res Pract 3: 8.

28. Parlakgumus H, Kilicdag E, Simsek E, Haydardedeoglu B, Cok T, et al (2014) Fertility outcomes of patients with early stage endometrial carcinoma. J Obstet Gynaecol Res 40(1): 102-108.

29. Gallos I, Yap J, Rajkhowa M, Luesley D, Coomarasamy A, et al. (2012) Regression, relapse, and live birth rates with fertility-sparing therapy for endometrial cancer and atypical complex endometrial hyperplasia: a systematic review and metaanalysis. Am J Obstet Gynecol 207(4) 266.e1-e12.

30. Kesterson J, Fanning J (2012) Fertility-sparing treatment of endometrial cancer: options, outcomes and pitfalls. J Gynecol Oncol 23(2): 120-124

31. Larson D, Johnson K, Broste S, Krawisz B, Kresl JJ (1995) Comparison of D\&C and office endometrial biopsy in predicting final histopathologic grade in endometrial cancer. Obstet Gynecol 86(1): 38-42.

32. Leitao M, Kehoe S, Barakat R, Alektiar K, Gattoc L, et al. (2009) Comparison of D\&C and office endometrial biopsy accuracy in patients with FIGO grade 1 endometrial adenocarcinoma. Gynecol Oncol 113(1): 105-108.

33. Falcone F, Laurelli G, Losito S, Di Napoli M, Granata V, et al. (2017) Fertility preserving treatment with hysteroscopic resection followed by progestin therapy in young women with early endometrial cancer. J Gynecol Oncol 28(1): e2.

34. Rodolakis A, Biliatis I, Morice P, Reed N, Mangler M, et al. (2015) European Society of Gynecological Oncology Task Force for Fertility Preservation: Clinical Recommendations for Fertility-Sparing Management in Young Endometrial Cancer Patients. Int J Gynecol Cancer 25(7): 1258-1265.

35. Adonakis G, Androutsopoulos G, Paschopoulos M (2015) The role of hysteroscopy in endometrial cancer. Int J Clin Ther Diagn S1(4): 12-16.

36. Grigoriadis C, Zygouris D, Androutsopoulos G, Arnogiannaki N, Terzakis E (2012) Hysteroscopical findings and occurrence of malignancy in postmenopausal women diagnosed with endometrial polyps: a 5 year review. Maturitas 71(1): S26.

37. Shah M, Wright J (2011) Management of endometrial cancer in young women. Clin Obstet Gynecol 54(2): 219-225.

38. Kim S, Kim H, Song Y, Kang S, Lee HP (1995) Detection of deep myometrial invasion in endometrial carcinoma: comparison of transvaginal ultrasound, CT, and MRI. J Comput Assist Tomogr 19(5): 766-772.

39. Rockall A, Qureshi M, Papadopoulou I, Saso S, Butterfield N, et al. (2016) Role of Imaging in Fertility-sparing Treatment of Gynecologic Malignancies. Radiographics 36(7): 2214-2233.

40. Kinkel K, Kaji Y, Yu K, Segal M, Lu Y, et al. (1999) Radiologic staging in patients with endometrial cancer: a meta-analysis. Radiology 212(3): 711-718.

41. Deng L, Wang Q, Chen X, Duan X, Wang W, et al. (2015) The combination of diffusion- and T2-weighted imaging in predicting deep myometrial invasion of endometrial cancer: A systematic review and metaanalysis. J Comput Assist Tomogr 39(5): 661-673.

42. Alcazar J, Orozco R, Martinez-Astorquiza Corral T, Juez L, Utrilla-Layna J, et al. (2015) Transvaginal ultrasound for preoperative assessment of myometrial invasion in patients with endometrial cancer: a systematic review and meta-analysis. Ultrasound Obstet Gynecol 46(4): 405-413.

43. Park J, Nam J (2015) Progestins in the fertility-sparing treatment and retreatment of patients with primary and recurrent endometrial cancer. Oncologist 20(3): 270-278.

44. Ushijima K, Yahata H, Yoshikawa H, Konishi I, Yasugi T, et al. (2007) Multicenter phase II study of fertility-sparing treatment with medroxyprogesterone acetate for endometrial carcinoma and atypical hyperplasia in young women. J Clin Oncol 25(19): 2798-803.

45. Koskas M, Uzan J, Luton D, Rouzier R, Darai E (2014) Prognostic factors of oncologic and reproductive outcomes in fertility-sparing management of endometrial atypical hyperplasia and adenocarcinoma: systematic review and meta-analysis. Fertil Steril 101(3): 785-794.

46. Randall T, Kurman R (1997) Progestin treatment of atypical hyperplasia and well-differentiated carcinoma of the endometrium in women under age 40. Obstet Gynecol 90(3): 434-440.

47. Kaku T, Yoshikawa H, Tsuda H, Sakamoto A, Fukunaga M, et al. (2001) Conservative therapy for adenocarcinoma and atypical endometrial hyperplasia of the endometrium in young women: central pathologic review and treatment outcome. Cancer Lett 167(1): 39-48.

48. Minig L, Franchi D, Boveri S, Casadio C, Bocciolone L, et al. (2011) Progestin intrauterine device and GnRH analogue for uterus-sparing treatment of endometrial precancers and well-differentiated early endometrial carcinoma in young women. Ann Oncol 22(3): 643-649.

49. Koskas M, Azria E, Walker F, Luton D, Madelenat P, et al. (2012) Progestin treatment of atypical hyperplasia and well-differentiated adenocarcinoma of the endometrium to preserve fertility. Anticancer Res 32(3): 1037-1043. 


\section{Cancer Therapy \& Oncology International Journal}

50. Park J, Kim D, Kim J, Kim Y, Kim K, et al. (2013) Long-term oncologic outcomes after fertility-sparing management using oral progestin for young women with endometrial cancer (KGOG 2002). Eur J Cancer 49(4): 868-874

51. Zapardiel I, Cruz M, Diestro M, Requena A, Garcia-Velasco J (2016) Assisted reproductive techniques after fertility-sparing treatments in gynaecological cancers. Hum Reprod Update 22(3).

52. Wethington S, Sonoda Y, Park K, Alektiar K, Tew W, et al. (2013) Expanding the indications for radical trachelectomy: a report on 29 patients with stage IB1 tumors measuring 2 to 4 centimeters. Int J Gynecol Cancer 23(6): 1092-1098.
53. Chao A, Chao A, Wang C, Lai C, Wang HS (2011) Obstetric outcomes of pregnancy after conservative treatment of endometrial cancer: case series and literature review. Taiwan J Obstet Gynecol 50(1): 62-66.

54. Chen M, Jin Y, Li Y, Bi Y, Shan Y, et al. (2016) Oncologic and reproductive outcomes after fertility-sparing management with oral progestin for women with complex endometrial hyperplasia and endometrial cancer. Int J Gynaecol Obstet 132(1): 34-38

55. Navarria I, Usel M, Rapiti E, Neyroud-Caspar I, Pelte M, et al. (2009) Young patients with endometrial cancer: how many could be eligible for fertility-sparing treatment? Gynecol Oncol 114(3): 448-451.

Your next submission with Juniper Publishers will reach you the below assets

- Quality Editorial service

- Swift Peer Review

- Reprints availability

- E-prints Service

- Manuscript Podcast for convenient understanding

- Global attainment for your research

- Manuscript accessibility in different formats

( Pdf, E-pub, Full Text, Audio)

- Unceasing customer service

Track the below URL for one-step submission https://juniperpublishers.com/online-submission.php 